\title{
Increasing Surface Hardness of AISI 1045 Steel by AIH-FPP/Plasma Nitriding Treatment
}

\author{
Shoichi Kikuchi ${ }^{1}$, Takahiro Fukuoka ${ }^{2, * 1}$, Takuma Sasaki ${ }^{2, * 1}$, Jun Komotori ${ }^{3, * 2}$, \\ Kengo Fukazawa ${ }^{4}$, Yoshitaka Misaka ${ }^{4}$ and Kazuhiro Kawasaki ${ }^{4}$ \\ ${ }^{1}$ Department of Mechanical Engineering, College of Science and Engineering, Ritsumeikan University, Kusatsu 525-8577, Japan \\ ${ }^{2}$ Graduate School of Science and Technology, Keio University, Yokohama 223-8522, Japan \\ ${ }^{3}$ Department of Mechanical Engineering, Faculty of Science and Technology, Keio University, Yokohama 223-8522, Japan \\ ${ }^{4}$ Research and Development Center, Neturen Co., Ltd., Hiratsuka 254-0013, Japan
}

In order to increase surface hardness of AISI 1045 steel, a new hybrid surface modification; combination of atmospheric-controlled induction-heating fine particle peening (AIH-FPP) and plasma nitriding, was developed. Surface microstructures of plasma nitrided specimens pre-treated with AIH-FPP using $\mathrm{Cr}$ shot particles were characterized by an optical microscope, a scanning electron microscope (SEM), an energy dispersive X-ray spectrometer (EDX) and X-ray diffraction analysis (XRD). As results, the nitrided layer was formed at the surface of the specimen with Cr diffused layer induced by AIH-FPP. This nitrided layer showed higher hardness than that of without AIH-FPP specimen. This was because CrN was formed at the surface of the AIH-FPP/Plasma nitriding treated specimen. And, the surface hardness of the nitrided layer tended to increase as the $\mathrm{Cr}$ concentration in the surface layer decreased. It was clarified that the pore formation during the AIH-FPP/Plasma nitriding treatment was inhibited by decreasing $\mathrm{Cr}$ concentration. These results suggest that the proposed hybrid surface treatment remarkably increases surface hardness of AISI 1045 steel. [doi:10.2320/matertrans.MBW201205]

(Received October 12, 2012; Accepted December 25, 2012; Published February 25, 2013)

Keywords: surface modification, atmospheric-controlled induction-heating fine particle peening (AIH-FPP), nitriding, hardness

\section{Introduction}

Nitriding, which is usually performed at a lower temperature (around $500^{\circ} \mathrm{C}$ ) than other heat treatments, has been widely used in various fields of engineering. Mainly, this treatment is performed to form high hardness layer and to improve the fatigue strength and wear resistance of steels ${ }^{1-7)}$ used for mechanical components. Especially, the formation of nitride precipitates, such as Al-, Cr-, V-nitrides, is very effective for increasing surface hardness of steels by nitriding.

In this study, in order to increase surface hardness of AISI 1045 steel without containing alloying elements which could precipitate as nitrides, a new hybrid surface modification was developed. In our previous study, we focused on shot particle transfer by fine particle peening (FPP) ${ }^{8-12)}$ and developed a surface treatment system that combined a high-frequency induction-heating (IH) system with FPP, enabling control of the process atmosphere (referred to as AIH-FPP). ${ }^{13)}$ This system can create a shot particle diffused layer on a metal substrate. ${ }^{13-16)}$ Therefore, it is possible that nitriding could create extremely high hardness layer on the AISI 1045 steel with Cr diffused layer induced by AIH-FPP.

The aim of this study is to examine the effect of the proposed hybrid surface modification; combination of AIHFPP and plasma nitriding, on the characteristics of the surface modified layer of the AISI 1045 steel. Moreover, the mechanism of forming high hardness layer by AIH-FPP/ Plasma nitriding treatment is discussed.

\footnotetext{
${ }^{* 1}$ Graduate Student, Keio University

${ }^{* 2}$ Corresponding author, E-mail: komotori@mech.keio.ac.jp
}

\section{Experimental Procedure}

The material used in this study was AISI 1045 steel with the chemical composition shown in Table 1. The microstructure of AISI 1045 steel is shown in Fig. 1. Steel bars, $15 \mathrm{~mm}$ in diameter, were machined into $4 \mathrm{~mm}$-thick disks. These specimens were polished with emery paper (\#320 to $\# 1200$ ), and were then mirror-finished using $\mathrm{SiO}_{2}$ suspension.

Figure 2 shows a schematic illustration of the AIH-FPP system. ${ }^{13)}$ The specimen was set into the heating coil and the atmosphere in the chamber was replaced by supplying argon gas through the FPP nozzle. After the oxygen meter (measuring tolerance $\pm 0.3 \%$ ) indicated $0.0 \%, \mathrm{Cr}$ shot particles $(30-50 \mu \mathrm{m}$ in diameter), as shown in Fig. 3, were peened by the AIH-FPP system at $900^{\circ} \mathrm{C}$ in an argon atmosphere. The AIH-FPP condition is shown in Fig. 4 and Table 2. In this study, AIH-FPP was performed under various heating time conditions in order to prepare 3 types of specimens which show different $\mathrm{Cr}$ concentration at the top surface. The plasma nitriding was then performed at $500^{\circ} \mathrm{C}$

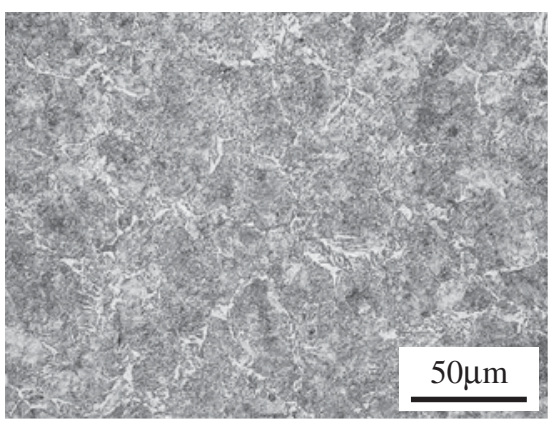

Fig. 1 Optical micrograph of AISI 1045 steel etched with 3\% Nital solution. 
Table 1 Chemical composition of AISI 1045 steel (mass $\%$ ).

\begin{tabular}{cccccccccccccccc}
\hline $\mathrm{C}$ & $\mathrm{Si}$ & $\mathrm{Mn}$ & $\mathrm{P}$ & $\mathrm{S}$ & $\mathrm{Ni}$ & $\mathrm{Cr}$ & $\mathrm{Mo}$ & $\mathrm{Cu}$ & $\mathrm{Ti}$ \\
\hline 0.45 & 0.20 & 0.71 & 0.018 & 0.026 & 0.04 & 0.13 & 0.01 & 0.09 & 0.002 & 0.002 & $\mathrm{Bal}$ & \\
\hline
\end{tabular}

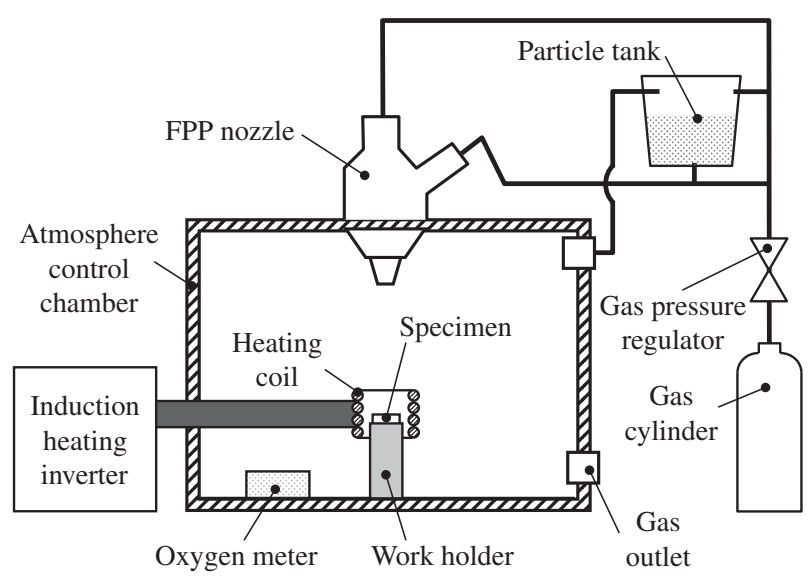

Fig. 2 Schematic illustration of atmospheric-controlled IH-FPP treatment system. $^{13)}$

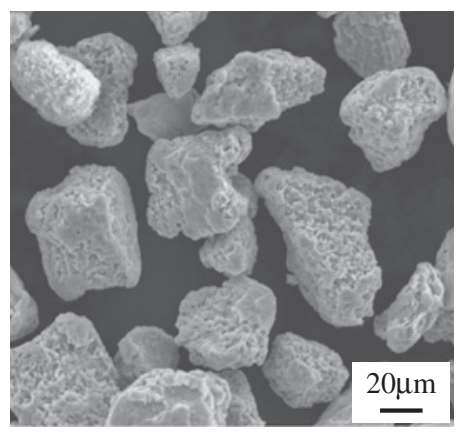

Fig. 3 SEM micrograph of chromium shot particles.

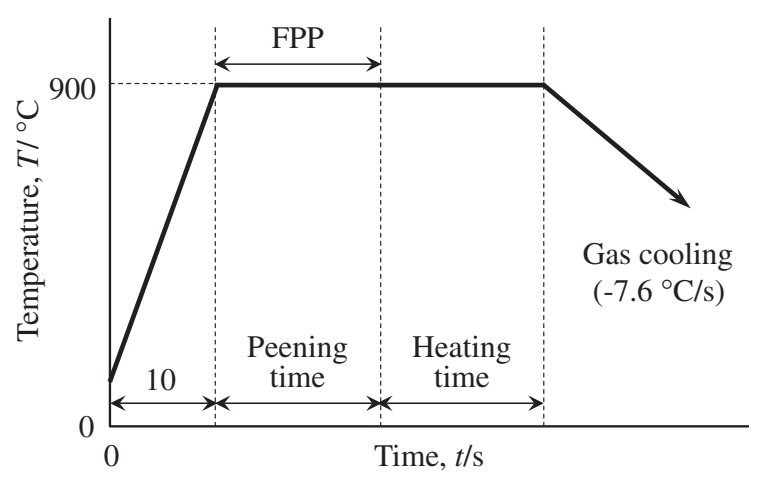

Fig. 4 Thermal condition of AIH-FPP treatment.

Table 2 AIH-FPP conditions.

\begin{tabular}{cc}
\hline Peening pressure, $p / \mathrm{MPa}$ & 0.5 \\
Peening time, $t / \mathrm{s}$ & 30 \\
Particle supply rate, $m /(\mathrm{g} / \mathrm{s})$ & 0.2 \\
Nozzle distance, $L / \mathrm{mm}$ & 100 \\
Heating time, $t / \mathrm{s}$ & $30,60,90$ \\
\hline
\end{tabular}

for $8.5 \mathrm{~h}$ after the AIH-FPP treatment. And, plasma nitrided specimen without AIH-FPP was also prepared (referred to as the $\mathrm{N}$ series).

The microstructural characteristics of the modified specimen surface were examined using an optical microscope, a scanning electron microscope (SEM) and an energy dispersive X-ray spectrometer (EDX). The crystal structures of the specimens were identified using X-ray diffraction (XRD) with $\mathrm{CuK} \alpha$ radiation (wavelength: $0.154 \mathrm{~nm}$ ).

\section{Results and Discussions}

\subsection{Evaluation of the surface modified layer created by AIH-FPP}

Figure 5 shows the SEM micrographs and the results of EDX analyses, with $\mathrm{Cr}$ and $\mathrm{Fe}$ maps observed at the longitudinal sections of the AIH-FPP treated specimens etched with 3\% Nital solution. These figures show a smooth layer is observed near the surface and the layer contains $\mathrm{Cr}$ and $\mathrm{Fe}$ elements. This result indicates that AIH-FPP treatment supplies $\mathrm{Cr}$ element on the specimen's surface. And the thickness of the surface modified layer was increased with increasing heating time in AIH-FPP. Figure 6 shows the relationship between heating time in AIH-FPP and the $\mathrm{Cr}$ concentration at the top surface of the AIH-FPP treated specimens. The $\mathrm{Cr}$ concentration became low as heating time was increased. This was because the $\mathrm{Cr}$ element in shot particles transferred on the surface was diffused into the material during the heating process in AIH-FPP. These specimens are referred to as the High series, Middle series and Low series corresponding to the $\mathrm{Cr}$ concentration, respectively.

In order to examine the characteristics of the AIH-FPP modified layer in more detail, XRD analysis was performed. Figure 7 presents XRD patterns obtained for surface layers of the untreated specimen (Fig. 7(a)) and AIH-FPP treated specimens (Figs. 7(b), 7(c), 7(d)). In every specimen, similar diffraction patterns were observed. The diffraction peak of the base metal $(\mathrm{Fe})$ was revealed, but the diffraction peaks of the shot particle $(\mathrm{Cr})$ and $\mathrm{Cr}-\mathrm{Fe}$ compounds were not detected. These results indicate that the $\mathrm{Cr}$ diffused layer is formed on the AIH-FPP treated specimen.

\subsection{Evaluation of surface layer created by the AIH- FPP/Plasma nitriding treatment}

In the previous section, the $\mathrm{Cr}$ diffused layers, whose thickness and $\mathrm{Cr}$ concentration were different, were formed on the AISI 1045 steel by AIH-FPP treatment. In order to evaluate the effect of AIH-FPP treatment on plasma nitriding behavior of AISI 1045 steel, plasma nitriding was performed on both AIH-FPP treated and untreated specimens.

Figure 8 shows the micro-Vickers hardness distribution of the plasma nitrided specimens at longitudinal section. In this figure, the plasma nitriding increased the hardness 


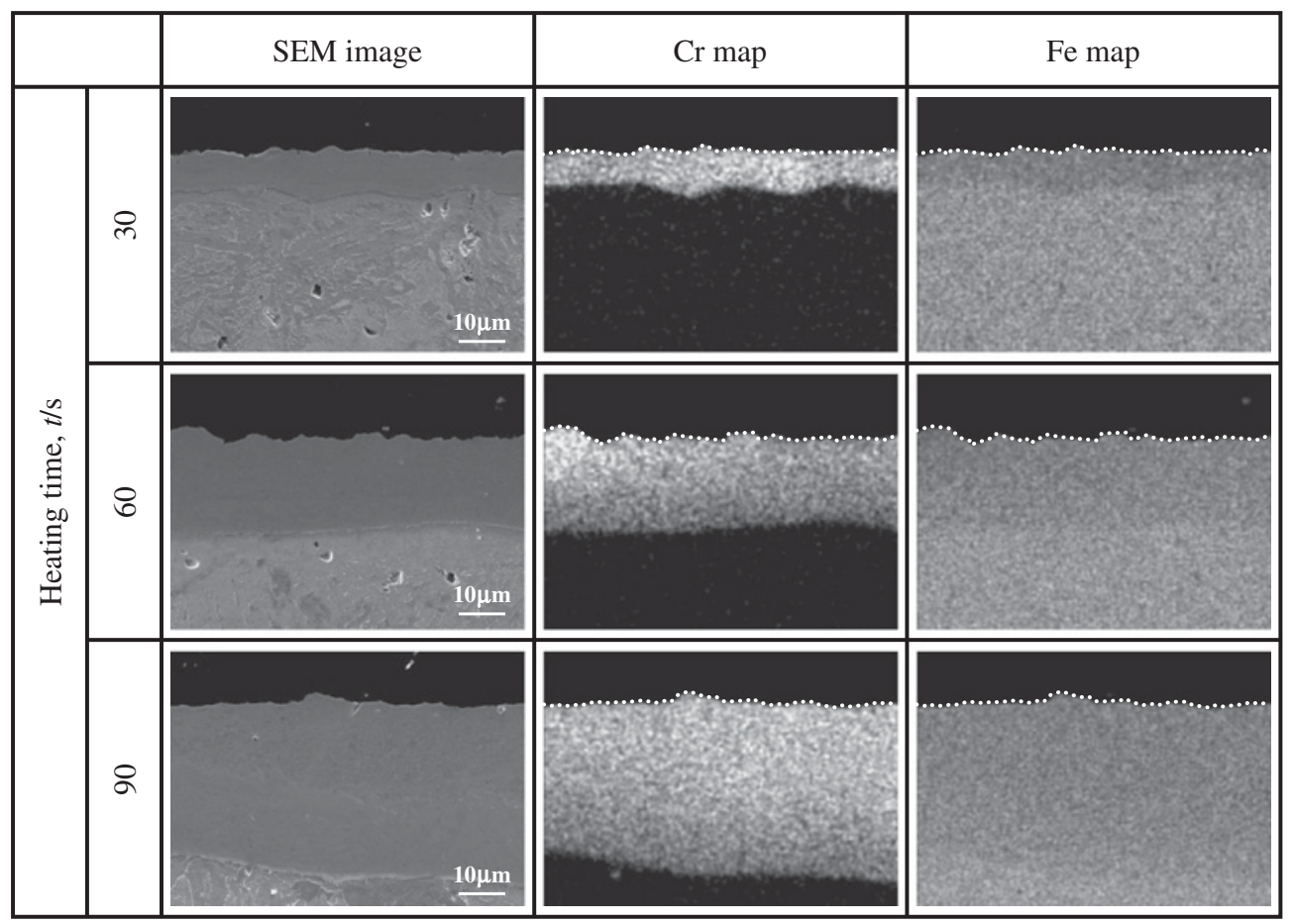

Fig. 5 SEM images and EDX maps observed at longitudinal sections of AIH-FPP treated specimens.

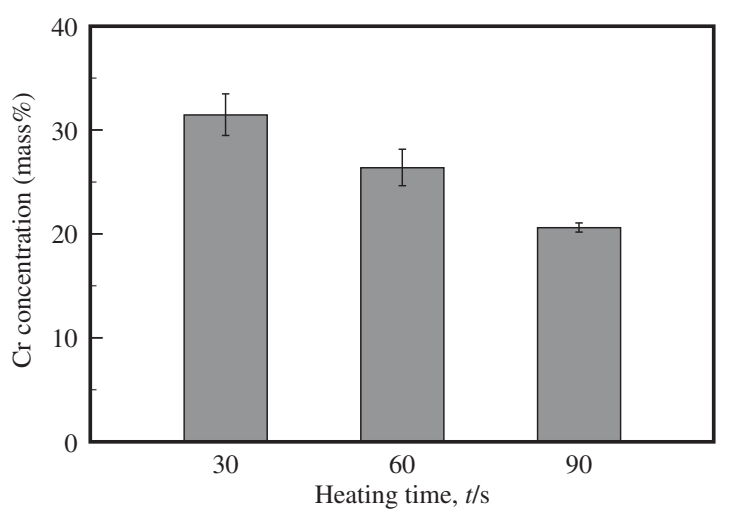

Fig. $6 \mathrm{Cr}$ concentration at the surface of the AIH-FPP treated specimens.

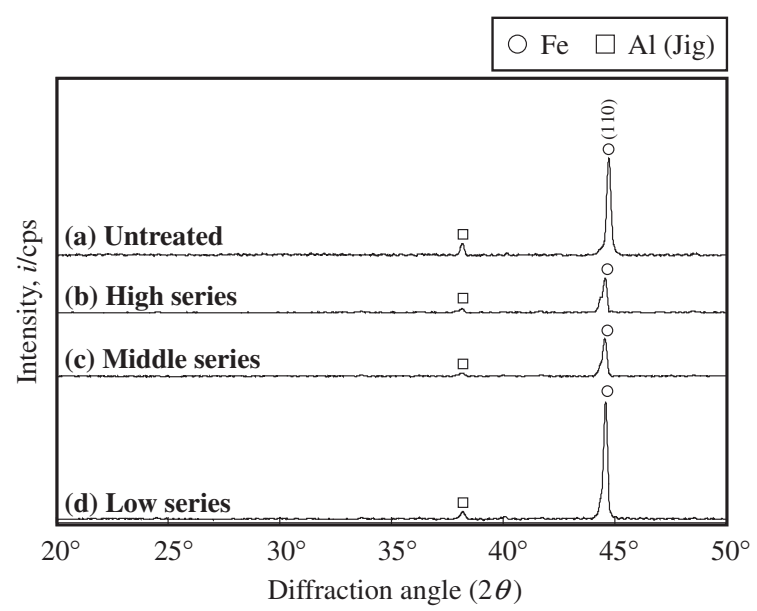

Fig. 7 X-ray diffraction patterns of the untreated and AIH-FPP treated specimens.

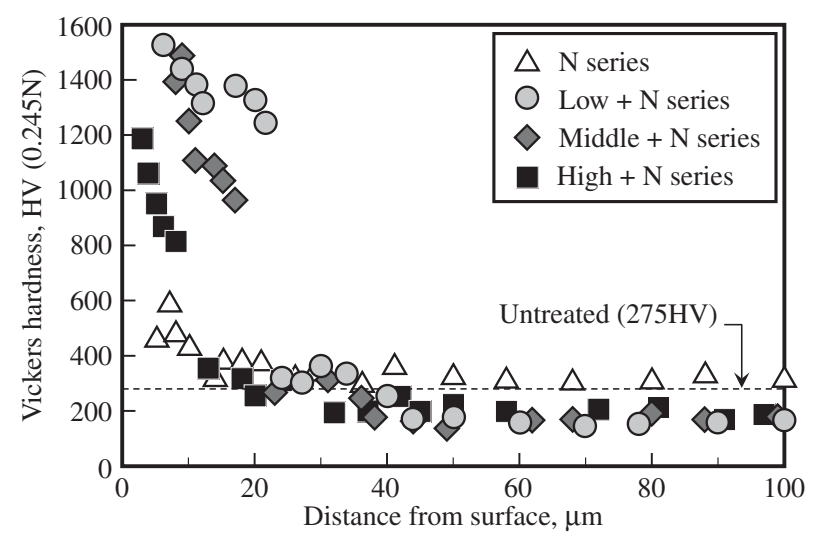

Fig. 8 Distributions of Vickers hardness of the AIH-FPP/Plasma nitriding treated specimens and $\mathrm{N}$ series.

of specimens near the surface. The surface hardness of the AIH-FPP/Plasma nitriding treated specimens $(\mathrm{High}+\mathrm{N}$, Middle $+\mathrm{N}$ and Low $+\mathrm{N}$ series) was high in comparison to that of the $\mathrm{N}$ series. And surface hardness tended to be increased with decreasing the $\mathrm{Cr}$ concentration.

Figure 9 shows typical microstructural features of the plasma nitrided specimens observed with an optical microscope after etching with a $3 \%$ Nital solution. These figures show that the black layer is clearly observed on the AIHFPP/Plasma nitriding treated specimens. This black layer was a nitrided layer corresponded to the high hardness region, as shown in Fig. 8. And the thickness of nitrided layer was increased with increasing heating time in AIH-FPP.

To examine the characteristics of the microstructure of the plasma nitrided specimens in more detail, XRD analysis was performed. Figure 10 presents XRD patterns obtained for surface layers of the AIH-FPP/Plasma nitriding treated 

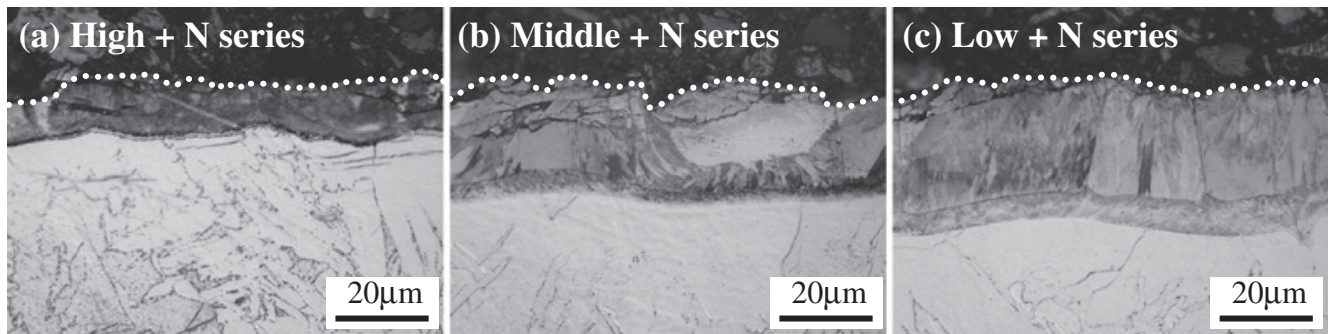

Fig. 9 Longitudinal optical micrographs of the AIH-FPP/Plasma nitriding treated specimens.

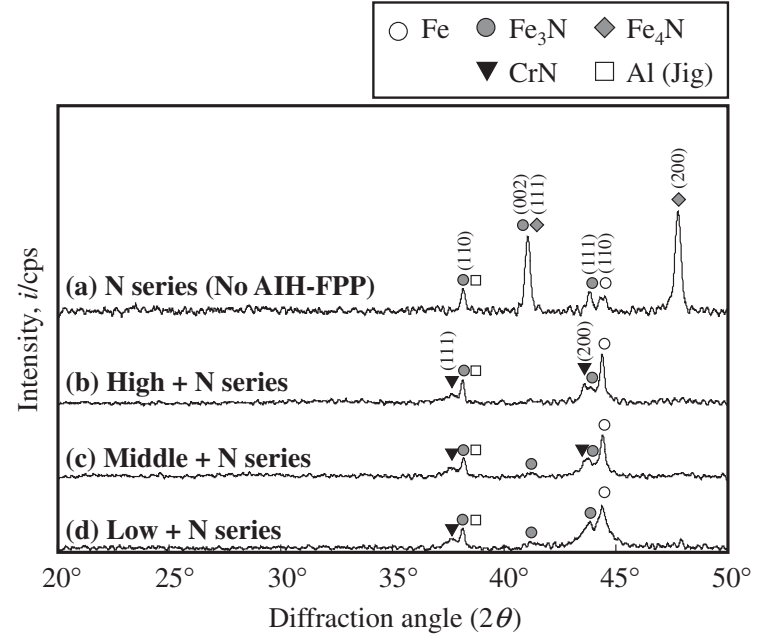

Fig. 10 X-ray diffraction patterns of the AIH-FPP/Plasma nitriding treated specimens and $\mathrm{N}$ series.

specimens and $\mathrm{N}$ series. In every specimen, the diffraction peaks of iron-nitrides were detected. Moreover, the peak of $\mathrm{CrN}$ was clearly observed on the AIH-FPP/Plasma nitriding treated specimens (Figs. 10(b), 10(c), 10(d)). The peak intensity of $\mathrm{CrN}(200)$ was increased with increasing the $\mathrm{Cr}$ concentration. It was clarified that AIH-FPP/Plasma nitriding treatment created chromium nitride on the AISI 1045 steel, resulting in the formation of high hardness layer.

\subsection{Mechanism of creating the high hardness layer using AIH-FPP/Plasma nitriding treatment}

In order to increase surface hardness of AISI 1045 steel, we performed AIH-FPP using $\mathrm{Cr}$ shot particles prior to plasma nitriding. This treatment enables the creation of high hardness layer containing chromium nitride. However, the hardness of the nitrided layer was decreased with increasing Cr concentration of the surface layer induced by AIH-FPP, as shown in Fig. 8. In this section, the mechanism of forming high hardness layer by AIH-FPP/Plasma nitriding treatment is discussed.

Figure 11 shows the SEM micrographs of the AIH-FPP/ Plasma nitriding treated specimens etched with 3\% Nital solution. The presence of the compound layer can be clearly observed near the surface. In the case of the High $+\mathrm{N}$ and Middle $+\mathrm{N}$ series (Figs. 11(a), 11(b)), cracks and pores were observed at the surface. On the other hand, the compound layer of the Low $+\mathrm{N}$ series did not possess cracks and pores (Fig. 11(c)).
In order to clarify the reason for forming pores in the compound layer of the High $+\mathrm{N}$ and Middle $+\mathrm{N}$ series, EDX analysis was performed. Figure 12 shows the results of EDX analyses with $\mathrm{Cr}$ maps corresponded to the SEM micrographs, as shown in Fig. 11. These figures show that $\mathrm{Cr}$ concentration is locally high surrounding the porous region in the $\mathrm{High}+\mathrm{N}$ and Middle $+\mathrm{N}$ series (indicating the arrow marks in Figs. 12(a), 12(b)). On the other hand, in the case of the Low $+\mathrm{N}$ series (Fig. 12(c)), which did not posses pores, $\mathrm{Cr}$ concentration showed constant inside the compound layer. Hosmani et al. ${ }^{17)}$ reported that pores in the compound layer were formed due to recombination of nitrogen atoms to $\mathrm{N}_{2}$ during the transformation of the ferrite matrix into iron nitrides surrounding $\mathrm{CrN}$ precipitates. Based on this report and results, in the case of the AIH-FPP treated specimens containing high $\mathrm{Cr}$ concentration, pores and cracks are easily formed in the compound layer, resulting in decreasing surface hardness. It was clarified that the pore formation during the subsequent plasma nitriding was inhibited by decreasing $\mathrm{Cr}$ concentration in the $\mathrm{Cr}$ diffused layer created by AIH-FPP.

Figure 13 schematizes the mechanism of forming surface layer by plasma nitriding and the proposed hybrid surface modification. In the case of the $\mathrm{N}$ series, only iron nitrides are formed (Fig. 13(a)). In contrast, in the case of the AIH-FPP/ Plasma nitriding treated specimens, the $\mathrm{Cr}$ element induced by AIH-FPP precipitates as $\mathrm{CrN}$, resulting in the formation of high hardness layer. However, when the $\mathrm{Cr}$ concentration of AIH-FPP treated surface is high, cracks and pores are created in the compound layer during the subsequent plasma nitriding (Fig. 13(b)). The pore formation could be inhibited by decreasing $\mathrm{Cr}$ concentration in the $\mathrm{Cr}$ diffused layer created by AIH-FPP (Fig. 13(c)). These results suggest that the proposed hybrid surface treatment remarkably increases surface hardness of AISI 1045 steel.

\section{Conclusion}

In order to increase surface hardness of AISI 1045 steel, a new hybrid surface modification; combination of AIH-FPP using $\mathrm{Cr}$ shot particles and plasma nitriding, was developed. The results are summarized as follows:

(1) Surface hardness of the AIH-FPP/Plasma nitriding treated specimen shows high in comparison to that of the only plasma nitrided specimen. This is because the AIH-FPP/Plasma nitriding treatment enables the formation of chromium nitride on the AISI 1045 steel's surface. 

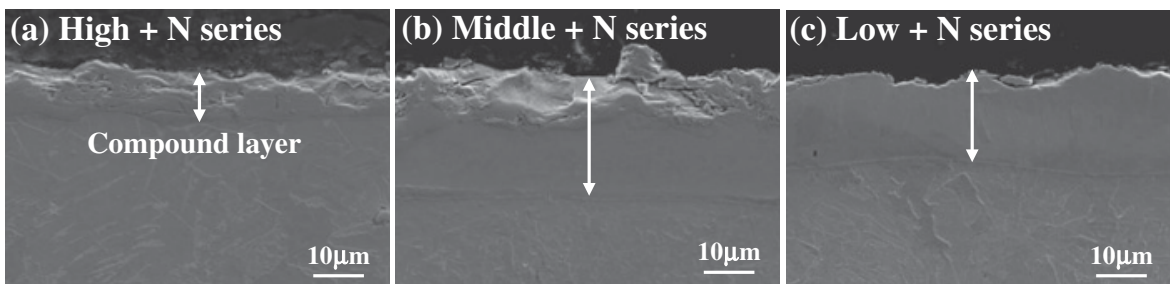

Fig. 11 Longitudinal SEM micrographs of the AIH-FPP/Plasma nitriding treated specimens.
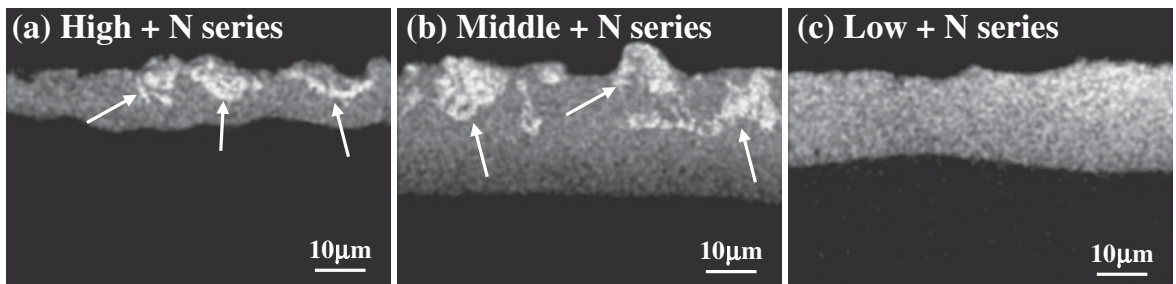

Fig. 12 EDX maps analyzed at the SEM micrograph shown in Fig. 11.

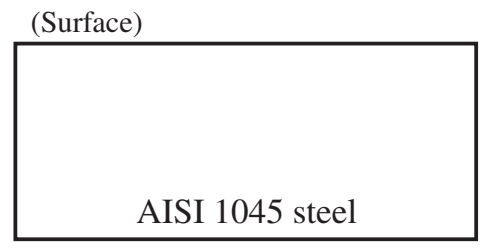

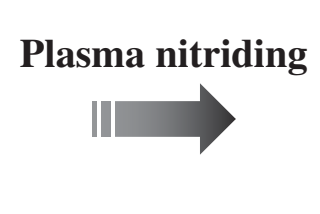

(a) Plasma nitriding

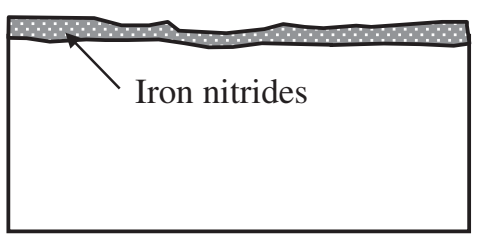

Plasma nitrided

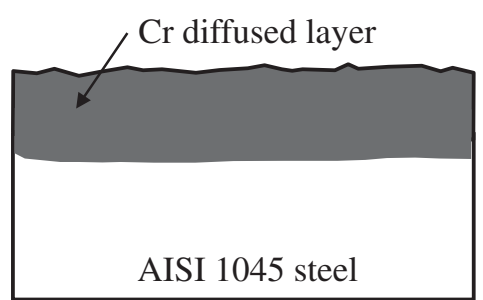

AIH-FPP treated

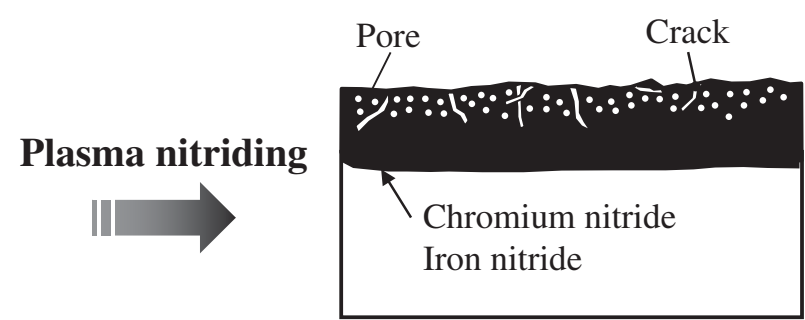

AIH-FPP + Plasma nitrided

(b) AIH-FPP (Diffused layer with high Cr concentration is formed at the surface) + Plasma nitriding

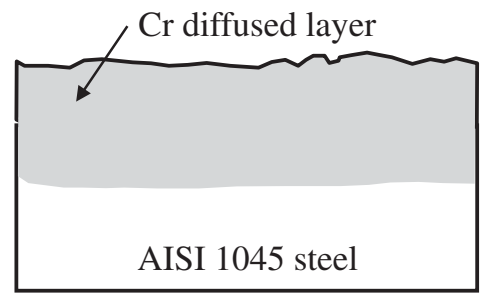

AIH-FPP treated

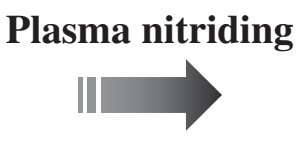

(c) AIH-FPP (Diffused layer with low Cr concentration is formed at the surface) + Plasma nitriding

Fig. 13 Schematic illustration showing the mechanism of forming surface modified layer created by AIH-FPP/Plasma nitriding treatment.

(2) In the case of the specimen containing high $\mathrm{Cr}$ concentration of Cr diffused layer induced by AIH-FPP, cracks and pores are created in the compound layer during the subsequent plasma nitriding. It is effective to form low $\mathrm{Cr}$ concentration diffused layer by AIH-FPP for increasing surface hardness of nitrided AISI 1045 steel.
(3) The characteristics of nitrided layers created by the AIH-FPP/Plasma nitriding treatment can be controlled by varying heating time in AIH-FPP. AIHFPP/Plasma nitriding treatment is a very efficient process to increase surface hardness of AISI 1045 steel. 


\section{REFERENCES}

1) K. Genel, M. Demirkol and M. Capa: Mater. Sci. Eng. A 279 (2000) 207-216

2) A. Alsaran, M. Karakan and A. Celik: Mater. Charact. 48 (2002) $323-$ 327.

3) M. Pellizzari, A. Molinari and G. Straffelini: Mater. Sci. Eng. A 352 (2003) 186-194.

4) W. P. Tong, C. Z. Liu, W. Wang, N. R. Tao, Z. B. Wang, L. Zuo and J. C. He: Scr. Mater. 57 (2007) 533-536.

5) A. Çelik and S. Karadeniz: Surf. Coat. Tech. 72 (1995) 169-173.

6) S. Kikuchi and J. Komotori: J. Solid Mech. Mater. Eng. 2 (2008) 1444 1450 .

7) S. Kikuchi, Y. Nakahara and J. Komotori: Int. J. Fatigue 32 (2010) 403-410.

8) Y. Kameyama, J. Komotori and E. Shimodaira: J. Mater. Testing Res. Association of Japan 48 (2003) 53-56.
9) Y. Kameyama and J. Komotori: J. Solid Mech. Mater. Eng. 2 (2008) 1338-1347.

10) Y. Kameyama and J. Komotori: Wear 263 (2007) 1354-1363.

11) Y. Kameyama and J. Komotori: J. Mater. Process. Tech. 209 (2009) 6146-6155.

12) H. Nanbu, S. Kikuchi, Y. Kameyama and J. Komotori: J. Solid Mech. Mater. Eng. 3 (2009) 328-335.

13) T. Ito, S. Kikuchi, Y. Kameyama, J. Komotori, K. Fukazawa, Y. Misaka and K. Kawasaki: J. Japan Inst. Metals 74 (2010) 533-539.

14) T. Fukuoka, Y. Ujiie, J. Komotori, K. Fukazawa, Y. Misaka and K. Kawasaki: Procedia Eng. 10 (2011) 1503-1508.

15) T. Fukuoka, S. Kikuchi, J. Komotori, K. Fukazawa, Y. Misaka and K. Kawasaki: J. Japan Inst. Metals 75 (2011) 372-378.

16) A. Sasago, S. Kikuchi, Y. Kameyama, J. Komotori, K. Fukazawa, Y. Misaka and K. Kawasaki: J. Japan Inst. Metals 72 (2008) 347-352.

17) S. S. Hosmani, R. E. Schacherl and E. J. Mittemeijer: Haerterei Tech. Mitt. 63 (2008) 139-146. 